\title{
ARTETERAPIA NA ASSISTÊNCIA DE ENFERMAGEM EM ONCOLOGIA: PRODUÇÕES, EXPRESSÕES E SENTIDOS ENTRE PACIENTES E ESTUDANTES DE GRADUAÇÃO
}

\author{
Art Therapy in Oncology's Nursing Care: Productions, Expressions and \\ Meanings among Patients and Graduation Students \\ Terapia con Arte en la Ayuda de Enfermería en Oncología: Producciones, \\ Expresiones y Sentidos entre Pacientes y Estudiantes de Graduación
}

\begin{abstract}
Resumo
0 objetivo deste artigo é relatar a experiência vivida por um grupo de alunas do Curso de Graduação em Enfermagem da Universidade Federal do Ceará, na disciplina Administração do Processo de Trabalho em Enfermagem II, na administração do ócio dos pacientes em um hospital de Fortaleza-CE. A experiência didática foi uma representação plástica a partir do Quadro de Referência Cognitivo-Comportamental realizado em abril de 2002, e teve como sujeitos sete pacientes e seis alunas de enfermagem. A criatividade artística dos pacientes fluiu em conseqüência do diálogo do artista com sua produção. A análise das produções artísticas foi complementada pelas observações das alunas. As obras produzidas foram interpretadas com a ajuda do teste de cores de Lüscher o que permitiu inferir o comportamento e os sentimentos exteriorizados nas cores variadas selecionadas pelos pacientes.
\end{abstract}

Palavras-chave: Terapia pela Arte. Cuidados de Enfermagem. Enfermagem Oncológica.

\begin{abstract}
The objective of this article is to report the experience lived by a group of students of the Course of Graduation in Nursing of the Federal University of Ceará (Brazil), in the Administration of the Process of Work in Nursing II discipline, in the administration of the idleness of the patients in a hospital of Fortaleza - Ceára, Brazil. The didactic experience was a plastic representation from the Cognitive and Behavioral Reference Picture carried through in April of 2002, and had as citizens seven patients and six students of nursing. The artistic creativity of the patients flowed in consequence of the dialogue of the artist with the production. The analysis of the artistic productions was complemented by the observations of the students. The produced pieces had been interpreted with the help of the test of colors from Lüscher which allowed infer in the behavior and in the feelings exteriorized in the varied colors selected by the patients.
\end{abstract}

Keywords:

Art Therapy. Nursing Care. Oncologic Nursing.

\section{Resumen}

El objetivo de este artículo es relatar la experiencia vivida por un grupo de alumnas del Curso de Graduación en Enfermería de la Universidad Federal del Ceará (Brasil), en la disciplina Administración del Proceso de Trabajo en Enfermería II, en la administración de la ociosidad de los pacientes en un hospital de Fortaleza - Ceára, Brasil. La experiencia didáctica fue una representación plástica desde el Cuadro de Referencia Cognoscitivo y del Comportamiento realizado en abril de 2002, y tenía como sujetos siete pacientes y seis alumnas de enfermería. La creatividad artística de los pacientes fluyó en consecuencia del diálogo del artista con su producción. El análisis de las producciones artísticas fue complementado por las observaciones de las alumnas. Las obras producidas habían sido interpretadas con la ayuda de la prueba de colores de Lüscher que permitió inferir en el comportamiento y en las sensaciones exteriorizadas en los colores variados seleccionados por los pacientes.

Palabras clave:

Terapia con Arte. Atención de Enfermería. Enfermería Oncológica. 


\section{INTRODUÇÃO}

0 ser humano, ao lado de suas necessidades biológicas, tem anseios profundos de ser amado e de ser importante para alguém. É desses anseios que se originam as outras necessidades. Além do mais, o homem esforça-se por atingir ou manter o sentido do eu, na procura do contato com você com aquele que dá importância, calor e carinho ao seu próprio eu. Quando tal ponte é construída, ele pode dar amor aos outros e realizar tudo aquilo que é capaz ${ }^{1}$

0 homem usa o corpo para expressar o mundo material. 0 corpo, em seu estado sólido, dispõe de componentes moleculares básicos que vibram numa freqüência baixa, o plano anímico apresenta freqüência de vibração média, e o plano mental tem freqüência mais alta². Explicando melhor, para que um tema que se degradou ao plano inferior de freqüência de vibração como sintoma corporal seja elevado ao nível anímico é preciso injetar-lhe energia. Há necessidade de mais energia, ainda, para elevá-lo ao plano mental.

Na interpretação dos sintomas de uma doença essa energia deve surgir sob a forma de conscientização e de entrega. No surgimento da doença, no processo contrário, a energia foi armazenada e produziu alteração nas funções normais da pessoa, manifestando-se por meio de sinais característicos e particulares - os sintomas. Isto acontece quando um tema, no plano inferior de freqüência de vibração se degradou como sintoma corporal ${ }^{2}$ produzindo a redução do nível de otimização da homeostase. Portanto, "a doença humana é qualquer redução do nível de otimização da homeostase do processo de troca de matéria, energia e informação de um sistema com 0 seu ecossistema e de seus subsistemas entre si"1:26.

Dizendo-se de outro modo, a doença surge quando se faz interpretações errôneas da realidade, levando à produção de disfunções nos processos mentais, no controle emocional, nas interações sociais, nas estratégias cognitivas e/ou na capacidade de desempenhar atividades. Assim, numa primeira dinâmica psicológica que o paciente experimenta, ele vê a doença como uma ameaça, isto é, como uma agressão, proveniente do seu próprio interior, que potencialmente lesa a imagem mental que tem de si mesmo. Em decorrência manifestam reações específicas chamadas mecanismos de defesa. Dentre eles aparecem com maior freqüência, a regressão (estado de dependência real dos outros), a formação reativa (mecanismo de defesa geralmente agressivo, que aparece em patologias mais longas) e a negação da própria doença ${ }^{3}$.

Com este entendimento de doença, as alunas de enfermagem, que realizavam suas práticas de administração no Hospital do Câncer do Ceará, começaram a refletir e a buscar uma forma de prestar assistência aos entes cuidados e a dar um sentido ao tempo ocioso dos pacientes de modo que resultasse em esperança, em alegria de viver. Perceberam que esse tempo ocioso causava angústia, temor, baixa auto-estima e baixa socialização em virtude de ficarem deitados no leito em silêncio, a maior parte do tempo, mesmo quando estavam em boas condições clínicas. Nessas condições, os indivíduos tinham naturalmente um tempo para liberam seus pensamentos e sentimentos.
Partindo do pressuposto de que os pensamentos e sentimentos do homem exprimem-se mais por imagens do que por palavras ${ }^{4,5}$, e sabendo que $\mathrm{o}$ inconsciente é aliviado por meio da projeção de imagens espontâneas em expressão gráfica ou plástica, a equipe (professoras e alunas) decidiu pela promoção de uma atividade auto-expressiva categorizada como arteterapia.

Entretanto, a definição do termo, é insuficiente para dar conta da especificidade de seu campo de ação, pois os conhecimentos e as práxis necessárias pertencem a três domínios: ao da técnica das atividades plásticas, ao da psicologia da representação e da expressão e, ao da arte, sua significação e sua história4.

Arteterapia é qualquer tratamento psicoterapêutico que utilize como mediação a expressão artística (dança, teatro, música, etc) ou as representações plásticas (pintura, desenho, gravura, modelagem, máscaras, marionetes.). A expressão artística tem em comum a objetivação da representação visual do domínio figurativo a partir da transformação da matéria. ${ }^{4}$. A arteterapia compreende várias técnicas dentre as quais, a colagem $^{6}$, selecionada aqui como atividade auto-expressiva.

Ao decodificar o termo arteterapia em sua raiz tem-se a Arte - entendida como tendo a função de interpretar o mundo, provocar emoção, reflexão, explicar e refletir as histórias humanas. Tem também a função de representar crenças e homenagear idéias e pessoas ${ }^{7}$. A arte, através de sua história e de suas variações, apresenta diferentes códigos de significação onde as produções individuais podem encontrar seu sentido ${ }^{7}$. A abordagem artística supõe uma atitude estética e levanta hipóteses sobre a função das imagens, isto é, sobre a comunicação simbólica na vida humana. Cada estilo constitui uma tentativa plástica de dar resposta aos grandes problemas humanos.

E o sufixo terapia - que completa a palavra arteterapia, compreende a dimensão psíquica sem a qual nenhuma modificação duradoura do comportamento poderia ser considerada ${ }^{4}$. Assim, o trabalho em arteterapia centra-se no sujeito pesquisado, a fim de que ele encontre e elabore um universo de imagens significantes de seus conflitos subjetivos. Tal procedimento decorre da importância de se dar ao sujeito pesquisado os meios de simbolizar os termos de um conflito, através de atividades auto-expressivas.

A experiência didática que está sendo relatada foi considerada de muita importância por partir da concepção de que a arteterapia centra-se no sujeito pesquisado, na ânsia de ajudá-lo a encontrar e a elaborar o universo de imagens significantes de seus conflitos subjetivos. De dar ao sujeito pesquisado, os meios de simbolizar seus conflitos por meio de atividades auto-expressivas. Foi considerado relevante para a arte de administrar dos enfermeiros, posto que a valorização do tempo livre das pessoas determina o destino cultural e econômico do ser humano, sobretudo, quando leva em conta que 0 input proveniente do ambiente afeta a cogniçãa $0^{7}$

A atividade didático-pedagógica desenvolvida teve por finalidade realizar uma atividade auto-expressiva com arteterapia como estratégia para o ensino de administração em enfermagem; refletir sobre as repercussões de uma atividade auto-expressiva com arteterapia com vistas a pensá- 
la como estratégia para administração do ócio de pacientes internados e dar oportunidade às alunas-participantes da atividade de vivenciarem uma experiência humanizadora.

Já, este trabalho tem por objetivo relatar a inovadora experiência didática vivida por um grupo de alunas do Curso de Graduação em Enfermagem da Universidade Federal do Ceará, disciplina Administração do Processo de Trabalho em Enfermagem II, na administração do ócio dos pacientes em um hospital de Fortaleza- CE.

\section{ASPECTOS TEÓRICOS E METODOLOGIA}

Este trabalho trata de um relato de experiência vivenciado por uma equipe de professores e alunos da disciplina Administração do Processo de Trabalho em Enfermagem, do $5^{\circ}$ semestre do Curso de Enfermagem da Faculdade de Farmácia, Odontologia e Enfermagem da Universidade Federal do Ceará.

A atividade de ensino aplicada no campo de prática baseouse no referencial teórico-metodológico denominado Quadro de Referência Cognitivo-Comportamental da Arteterapia (QRA). Este quadro fundamenta-se na suposição da existência de uma ligação, no ser humano, entre pensamentos, comportamentos e sentimentos ${ }^{8}$. Quando o indivíduo se sente mal consigo mesmo, ou diante de uma situação, sentimentos negativos são produzidos nele levando-o ao estresse, e inibem qualquer ação que interromperia o ciclo negativo. Se esses pensamentos e sentimentos estiverem relacionados com as atividades do diaa-dia estabelece-se um ciclo disfuncional, no qual a pessoa sente que não agüenta mais, e deixará de tentar reagir, provando a si mesma que seu pensamento negativo original é correto ${ }^{8}$.

Para entender este fenômeno, isto é, a ligação entre pensamento, comportamento e sentimentos é necessário compreender o homem como um sistema biológico aberto, integrado por vários subsistemas, capaz de trocas de matéria, energia e informação com o seu ecossistema, dotado de dispositivos homeostáticos e reprodutivos, de natureza teleológica, visando preservar e prolongar a vida e, perpetuar a espécie ${ }^{1}$. Os mecanismos internos da homeostase servem como retaguarda para o terapeuta, mas não são sua principal preocupação. Para manter a homeostase, o indivíduo deve comer, beber, evitar o perigo, etc. Embora essas ações sejam parcialmente controladas pelos processos corporais automáticos, elas requerem a participação ativa do indivíduo para assegurar a obtenção das necessidades de sobrevivência.

A experiência didática foi realizada em abril de 2002, no Hospital do Câncer do Ceará, instituição privada que atende também, a pacientes segurados pelo SUS. Embora não seja uma instituição de ensino, ela permitiu a entrada dos alunos do Curso de Graduação em Enfermagem da Universidade Federal do Ceará para que, usando o campo, desenvolvessem suas aulas práticas.

Do total de sujeitos, composto por 79 pacientes internados no hospital, apenas sete sujeitos participaram do estudo. A turma de alunos na disciplina de Processo de Trabalho em Enfermagem II era de trinta e seis alunos, enquanto que, apenas seis foram escalados para aquele campo, acompanhados de uma das professoras da equipe. A seleção dos pacientes foi realizada por conveniência, respeitando-se os seguintes critérios: a) pacientes sob os cuidados do grupo de alunos; b) indivíduos disfuncionais que aceitassem ser ajudados a se tornarem funcionais por meio da análise dos processos cognitivos.

Os dados subjetivos foram coletados por meio de trabalhos artísticos. A expectativa era a de que os pacientes se empenhassem na obra artística, que conseguissem manifestar um sentido à vida por meio da percepção da estratégia cognitiva eficaz e, que viessem a substituir as estratégias negativas ou ineficazes que vinham adotando. A expectativa com relação às alunas-participantes foi de que tomassem conhecimento de mais um procedimento técnico que poderia ser empregado na assistência aos pacientes.

Embora a experiência não fosse produto de uma pesquisa planejada previamente, mas tivesse surgido de uma valorização de momentos dinâmicos e ricos de ensino-aprendizagem, a professora da equipe preocupou-se em solicitar autorização prévia do dirigente da instituição, que, ciente dos objetivos da experiência, deu a permissão necessária. Além disso, houve o cuidado em observar todos os princípios éticos relativos às pesquisas com seres humanos. Assim, o trabalho artístico foi realizado em quatro fases:

1) Reunião com os dois grupos de sujeitos envolvidos na tarefa, momento em que lhes foi informado o objetivo da experiência e perguntado se aceitariam participar. Todos consentiram e assinaram o Termo de Consentimento Livre e Esclarecido ocasião em que lhes foi garantido o direito ao anonimato e à desistência em qualquer etapa do processo;

2) Aplicação da técnica de colagem - atividade autoexpressiva por meio da qual fluiu a criatividade artística do paciente, através de representação plástica. A cada paciente foi entregue uma tábua de madeira nas dimensões $0,30 \mathrm{~cm} \times 0,40 \mathrm{~cm}$, sementes naturais de tipo e cor variados colocadas em pequenos copos descartáveis, caneta hidrocor colorida, e espátula de madeira para espalhar a cola branca;

3) Observação de cada paciente por duplas de alunas participantes, e registro em ficha da aparência, postura, expressão verbal e não-verbal dos pacientes, bem como de suas atitudes, interação com a atividade e com 0 próprio pesquisador (alunas);

4) Reunião de todo o grupo ao término da produção artística.

A caracterização do objeto (produção artística) e as diferentes percepções foram consideradas quanto a sua totalidade, isto é, quanto a ordenação em um espaço, e foram analisadas com base na interpretação do Teste de Cores de Lüscher ${ }^{8}$. 0 princípio do Teste de Cores de Lüscher consiste em obter informações psicológicas exatas sobre uma pessoa, por meio de suas preferências e rejeições às cores. A preferência por uma cor e a aversão a outra significam algo definido e refletem um estado atual de espírito, de equilíbrio glandular, ou ambas. Ao demonstrar preferência por esta ou aquela cor, a escolha muitas vezes é ditada pelas circunstâncias ${ }^{8}$.

Nesta experiência foi empregado o Teste Abreviado de Lüscher e não o teste integral. Resumidamente, este teste tem considerável poder para salientar os aspectos importantes da personalidade e para chamar atenção para as áreas de tensão 
psicológicas e fisiológicas existentes. As cores azul, amarelo, vermelho e verde são chamadas de cores "primárias psicológicas" e constituem as cores básicas do teste. Foram consideradas ainda, as "cores auxiliares" violeta, marrom, cinza-neutro e preto. Cada grupo estrutural dos pares de cores tem um significado próprio que independe da sua posição, mas que contribui para a interpretação dos resultados.

A interpretação do teste pela seqüência das oito cores foi realizada a partir do significado das oito cores $^{8: 54}$, do significado estrutural dos pares de cores ${ }^{8: 72}$ e da organização das tabelas de interpretação funcional da atitude: ${ }^{8: 99}$. Esta interpretação foi categorizada em: a) objetivos desejados ou comportamento ditado pelos objetivos desejados; $b$ ) comportamento apropriado para a situação presente; $c$ ) comportamento inadequado para a situação presente; d) características carregadas de ansiedade; e) comportamento resultante de tensão.

Para facilitar a compreensão dos resultados das atividades auto-expressivas, a análise foi organizada primeiro com a posição dos pacientes. A avaliação das alunas-participantes também foi objeto de descrição, após observarem diretamente o processo de criação das obras.

\section{RESULTADOS DA EXPERIÊNCIA}

0 primeiro grupo, constituído pelos pacientes participantes, havia sido submetido a processo cirúrgico configurado como agressivo, radical, ou mutilador. A interpretação da arte final, a cargo da professora coordenadora, foi feita com a ajuda do Teste de Cores de Lüscher ${ }^{8}$.

Para facilitar o entendimento do processo de composição e análise e interpretação das obras artísticas, far-se-á a descrição das produções artísticas auto-expressivas dos pacientes (a), seguida da respectiva interpretação pelo Teste de Cores de Luscher (b).

\section{Desenho de um pé de serigüela:}

(a) Descrição da produção artística: foi desenhado um pé de serigüela atrás de uma cerca baixa, um desenho elaborado com sementes de cor amarela pálida, ocupando apenas metade do espaço da tábua de madeira nas dimensões $0,30 \mathrm{~cm} \times 0,40 \mathrm{~cm} ; 0$ arbusto foi composto de copa arredondada bem delimitada composta por ervilhas verdes e caule grosso montado com sementes na cor amarela pastel. A paciente, ao falar sobre sua criação, assim se expressou: "Como é bom a gente esquecer que tá doente, que sente dor ... Eu adoro plantas. Eu nunca vou me esquecer daquele pé de serigüela de casa e, do jardim ...". A paciente acrescentou ainda que, quando criança subia no pé de serigüela levando bronca da mãe por temer que caísse. Sorriu ao lembrar da infância. Semblante cansado e fácies de dor. Buscou apoio nas lembranças alegres da infância, época em que se sentia forte, corajosa e livre de qualquer sofrimento. Procurou, com a atividade autoexpressiva, entender o presente, buscou apoio no passado para enfrentar o futuro.

(b) Interpretação: as cores verde e amarela em tom pastel indicam tensão e ansiedade conseqüentes do conflito entre esperança e necessidade. Percebe-se que o desapontamento e a perda de esperança têm dado origem a uma incerteza angustiante; há dúvida se as coisas melhorarão no futuro. 0 desapontamento e o medo de não valer a pena formular novas metas levam à ansiedade. 0 desenho exprime que a paciente tenta afirmar-se mediante o controle dos detalhes, num esforço para for talecer sua posição.

\section{Desenho de um homem de pé, ao lado de um pé de café:}

(a) Descrição da produção artística: vê-se um homem de pé, à direita da tábua onde foi feita a colagem, ao lado de um cafeeiro carregado de frutos verdes e vermelhos; 0 tronco grosso foi preenchido por grãos de girassol nas cores cinza, preto. Sobre o cafeeiro desenhou uma linha semicircular preenchida por grãos cinza e preto, representando o processo de secagem do fruto, que termina num montículo de grãos amarelos de onde saem raios vermelhos, simbolizando o término do processo de maturação e secagem dos grãos. A descrição do ciclo do café fez a paciente recordar que ainda é jovem, que está pronta para dar frutos, para vibrar com a vida, embora cheia de dor; a paciente aproveitou a oportunidade para explicar o assunto, conforme viu num programa de TV; fez referência a uma bandeja que tinha em casa com o desenho de um pé de café; e finalizou dizendo: "eu sei pintar, é só me dar papel e lápis de cor ..."; informou que já pintara o mesmo motivo em casa; a paciente procurou mostrar competência artística e ganhar a admiração das alunas. Apesar de seu mal-estar geral cumpriu a tarefa, foi comunicativa, interativa e criativa.

(b) Interpretação: a cor cinza e preta significam que a paciente sente que tem sido injusta e traída em suas esperanças; está descontente e revoltada com as circunstâncias presentes que considera uma afronta; está sob considerável tensão devido às exigências da situação presente e tenta livrar-se das coisas que a restringem ou tolhem; quer superar a sensação de vazio por estar separada dos seus e acredita que a vida tem muito a oferecer; acha que é bastante competente em qualquer ramo de atividade a que se dedique; 0 amarelo e vermelho significam que ela está angustiada pelo medo de que possam impedi-la de fazer o que quer; precisa de calma e tranqüila reafirmação para recuperar a confiança em si; presentemente, está ansiosa para causar boa impressão, mas também, temerosa pela dúvida quanto à possibilidade de conseguir.

\section{Desenho de um grande coração, do qual jorra sangue branco e saem quatros pequenos galhos verdes de flores:}

(a) Descrição da produção artística: grande coração traçado e composto com sementes de diversas cores: verde, vermelha, amarela, e branca; do centro externo e superior do coração saem quatros pequenos galhos verdes de flores, simulando raios plantados sobre o amarelo que contorna a parte central do coração; 0 contorno deste foi traçado com as cores: verde, vermelha, e amarela, alternadamente; a 
paciente explicou que o desenho representa o coração de Jesus; dele, sai do ângulo inferior direito, sangue branco; ela informa ser evangélica; a atividade deu à paciente a oportunidade de sentir-se produtiva, valorizada, satisfeita; a presença de amigos no Hospital a fez sentir-se feliz e esperançosa; preocupou-se em conseguir desenhar algo bonito e colorido; no final da produção pediu às alunas que escrevessem ao redor do coração, o nome de cada uma; mostrou-se animada e cooperativa o tempo todo.

(b) Interpretação: o verde da esperança estava explícito nos raios centrais que fluem do coração de seu Deus; esta cor escolhida na primeira posição significa que a pessoa quer impressionar; precisa ser considerada, precisa manterse firme e fazer o que quer a despeito de alguma oposição e resistência; sente-se sobrecarregada, cansada, por isto nada está conseguindo, mas continua mantendo sua posição; sente que a situação adversa é uma pressão real e tangível, intolerável e da qual quer fugir, mas não consegue tomar a decisão necessária; o verde com 0 amarelo indicam tensão e ansiedade conseqüentes aos conflitos entre esperança e necessidade, alternados com desapontamento intenso; ele dá origem a uma incerteza angustiante e a faz duvidar de que as coisas melhorarão no futuro; a cor amarela/vermelha significa que ela se considera uma vítima iludida e maltratada; mas, tenta convencer-se de que seu fracasso em conseguir prestígio e consideração é por culpa dos outros; o teste não considera a cor branca.

\section{Desenho de um homem entre um cachorro, uma lagartixa e uma galinha:}

(a) Descrição da produção artística: o desenho de um homem entre um cachorro, uma lagartixa e uma galinha, todos traçados com sementes amarelas; sob os elementos, o paciente escreveu seu nome completo e mais abaixo a data em que a obra foi feita na cor azul escuro; disse que só há pouco tempo conseguira morar em casa própria e não era de Fortaleza, mas conhecia esta cidade, pois, antigamente vinha com freqüência para cá; aproveitou a oportunidade para relatar passagens de sua vida confidenciando que tinha mágoas de seus pais por não o terem encaminhado, na época, à escola; até hoje não sabe escrever; desde o início da tarefa, mostrou-se muito interessado por tudo que acontecia a seu redor; ao começar a atividade referiu que estava indeciso quanto ao que desenhar; mas depois, deixou fluir a criatividade; à medida que o processo fluía narrava passagens de sua vida; fez questão de dizer que observou que o Hospital do Câncer conta com poucos médicos, mas, com muitas enfermeiras e cozinheiras; acrescentou que achava a comida boa; a cor que predominou em seus desenhos foi a amarela.

(b) Interpretação: a cor amarela indica haver necessidade de mudança em sua situação ou em suas relações, para que haja alívio da tensão resultantes de decepções que têm levado a descontroles; precisa sentir-se estável e evitar quaisquer decepção e temores de ser preterido ou de perder posição e prestígio; duvida que as coisas melhorem no futuro; a cor azul com a qual assinou o próprio nome significa ansiedade e insatisfação contínua, seja em seus empreendimentos, ou nas frustrações emocionais; deseja um estado de harmonia tranqüila e pacífica, que lhe ofereça calmo contentamento e sensação de participação; sente-se incapaz de criar o senso de participação de que precisa; reluta em expor sua vulnerabilidade, resistindo a este estado de coisas; mas, sente-se dependente da ligação; sente-se também incompreendido, desorientado e inquieto, o que o impulsiona a buscar novas condições ou relações, na esperança de que elas possam oferecer-lhe contentamento e paz de espírito; as alunas e professora não souberam interpretar o significado da observação feita pelo paciente de que 'o hospital conta com poucos médicos, mas, com muitas enfermeiras e cozinheiras.

\section{Desenho de uma pipa:}

(a) Descrição da produção artística: uma pipa (brinquedo feito de papel e talos que as crianças empinam ao vento), cujos retângulos foram alternadamente pintados em verde, amarelo / vermelho; o paciente explicou que costumava desenhar esse motivo quando era criança; a escolha consciente ou inconsciente do tema/desenho da época da infância - a pipa, parece indicar o desejo de voar, de estar acima da realidade, de voltar ao passado quando se sentia livre de qualquer grilhão; expressão tranqüila.

(b) Interpretação: as cores vermelha / amarela significa a busca de sucesso, estímulo e vida cheia de experiência; quer se desenvolver livremente e se libertar dos grilhões de si próprio; quer vencer e viver intensamente; gosta do contato com os outros e é entusiasta por natureza; é receptivo a tudo que é novo, moderno ou extravagante; tem muitos interesses e quer ampliar seus campos de atividade; é otimista quanto ao futuro; essas cores significam também, que está ansioso para causar boa impressão, e preocupado quanto à possibilidade de ser bem sucedido; 0 desapontamento e o temor de que não vale a pena formular novas metas, o tem levado à tensão e ansiedade; sente que tem direito à realização de seus sonhos, e se torna indefeso e angustiado, quando as circunstâncias Ihe são adversas; considera-se uma vítima iludida e maltratada; confunde esta dramatização com a realidade, mas tenta convencer-se de que seu fracasso em conseguir prestígio e consideração em seu meio é culpa dos outros; a cor verde atua como uma represa atrás da qual a excitação dos estímulos externos avoluma-se sem ter liberdade, aumentando a sensação de orgulho, de superioridade sobre os outros, de poder, de controlar os acontecimentos, ou pelo menos de ser capaz de controlá-los e dirigi-los; o verde significa também, que a tenacidade e a força de vontade necessária para enfrentar as dificuldades enfraqueceram; busca obter 0 reconhecimento e vencer a oposição; esse comportamento "verde" pode encontrar expressão na busca de condições melhores, como saúde melhorada, ou uma vida mais longa e mais útil para si próprio e para os outros.

\section{Desenho de uma rã de tamanho médio, em posição de saltar:}

(a) Descrição da produção artística: rã de tamanho médio, em posição de saltar traçada em tábua de madeira, 
preenchido com ervilhas verdes e com a frase "eu quero sair logo daqui"; abaixo da rã, está a assinatura do nome com letra azul escuro; ele expressou que não via a hora de deixar o hospital por causa da filha deficiente visual, que deixara em casa; disse: "quero me tratar logo, antes que vire coisa pior"; não trouxe roupa sobressalente ao se hospitalizar; paciente recém-admitido, desempregado, vivendo de "bicos"; no início da atividade mostrou-se retraído e muito preocupado com a situação da família; depois, interagiu com o grupo.

(b) Interpretação: como já foi dito o verde significa que a pessoa procura a determinação e a elasticidade da vontade necessárias para se estabelecer e se tornar independente a despeito das dificuldades da situação; quer vencer a oposição e obter reconhecimento; persistente, exige o que lhe é devido e se esforça para manter inata sua posição; a situação o impede de se firmar, mas sente que deve conformar-se com as circunstâncias; o azul significa que a situação ou relação atual é insatisfatória; mas, sente que é incapaz de criar o senso de participação de que precisa; permanece emocionalmente independente, mesmo quando envolvido numa relação próxima; mantém sua posição, mas é sujeito a pressão intolerável; necessita de cooperação e de realização emocional, sentindo que, na ausência delas, não há nada que possa fazer para melhorar a situação atual; quer fugir de tudo.

\section{Desenho de uma árvore com raízes finas, superficiais e copa frondosa:}

(a) Descrição da produção artística: desenho de uma árvore que o paciente diz tratar-se de uma carnaubeira, cujas raízes são finas, superficiais e estão à mostra; copa bem delineada composta com lentilhas marrons; caule reto e fino desenhado com lápis hidrocor azul marinho; acima da árvore ele escreveu seu nome com tinta azul escuro; seu semblante transmitia tranqüilidade.

(b) Interpretação: a cor marrom significa que a pessoa está à procura de libertação dos problemas e de um estado de tranqüilidade física em que possa relaxar e se recuperar; tem a necessidade insatisfeita de se aliar a outros, cujos padrões sejam tão elevados quanto os seus e de se sobressair do comum; este desejo de preeminência o isola e inibe em sua disposição de ser livremente franco; embora queira entregar-se e se libertar, ele considera isso como uma fraqueza a que deve resistir; acha que o autodomínio o elevará acima da gente comum e assegurará seu reconhecimento como personalidade singular e distinta; exige estima dos outros; o azul / marrom significam que a pessoa evita esforço excessivo e precisa de raízes, segurança e de companheirismo tranqüilo; é capaz de sentir satisfação física na atividade sexual, mas é inquieto e inclinado a ser retraído emocionalmente, o que o impede de se envolver profundamente; a falta de compreensão e apreciação faz com que sinta que não existe nenhum laço real, e o descontentamento produz uma sensibilidade irritável; quer se sentir mais seguro e mais à vontade; gostaria de fugir do que agora considera um laço deprimente e restabelecer sua própria individualidade; a ansiedade e a insatisfação contínua, seja em seus empreendimentos ou nas frustrações emocionais, têm produzido considerável tensão; procura fugir delas para uma situação segura e livre de conflitos, na qual possa descansar e se recuperar.

Finalizando, cada pessoa éúnica, apresenta diferentes maneiras de ser e de ver o mundo. 0 ser enquanto ser não é diferente quando acometido por uma doença invasiva e descaracterizante. Com a ajuda do Teste de Lüscher ${ }^{8}$ pôde-se demonstrar que a estrutura de uma cor é constante, sendo definida com o significado objetivo daquela cor. A cor permanece a mesma para todos.

Em relação as estudantes participantes da experiência, os resultados descritos a seguir evidenciam suas posições:

\section{(A) Quanto aos registros dos sentimentos, desejos e comportamentoos dos pacientes:}

As observações das alunas de enfermagem foram registradas em fichas individuais organizadas segundo a atitude dos pacientes quanto a aparência, postura, expressão verbal, expressão não-verbal, atitude de colaboração, interação com a atividade, interação paciente/aluna. Resultados das observações registradas: (1) quanto a aparência, dois pacientes queixaram-se ou demonstraram não estar bem, embora bem orientados; (2) quanto à postura, três pacientes, no início, estavam tensos ou em atitude isolada; (3) quanto a expressão verbal, um paciente manifestou desejo de sair logo do hospital; um manifestou preocupação com o desempenho da tarefa artística; quatro pacientes aproveitaram o desenho para fazer narrativas de suas vidas na infância ou adolescência; (4) quanto à expressão não-verbal dos pacientes, quatro mostraram-se sorridentes e, ao mesmo tempo, entristecidos; (5) com relação a atitude de colaboração, seis pacientes mostraram-se interessados e colaborativos; (6) quanto à interação com a atividade, todos os participantes envolveram-se na obra artística e aproveitaram para fazer algum comentário especial; quanto à interação paciente/aluna; todos mostraram-se simpáticos, comunicativos e confiantes.

\section{(B) Registros dos sentimentos e posturas das estudantes:}

Senti-me bastante feliz em ter presenciado a Sra. M. G. realizando este trabalho artístico; ver seu semblante se iluminar com tão simples atividade, poder expressar seu carinho por nós e pelas pessoas a quem ama e quer que permaneçam perto dela. Desenhou um coração colorido escrito "coração de Jesus", demonstrando sua fé em Deus e, principalmente na vida. Foi muito gratificante sentir tais sensações e constatar, neste momento único e especial para mim, como acadêmica, que ainda tenho muito a aprender na minha prática como enfermeira (Aluna A).

Talvez, com esse trabalho, nós estudantes de enfermagem possamos nos certificar do valor da Enfermagem e da sua abrangência. Foi o melhor procedimento que já fiz nos últimos anos. Particularmente, me emocionei primeiro por ver o valor das pequenas coisas; depois, por constatar que cada 
um de nós pode fazer alguém feliz, e ver esse alguém grato por trazer-the felicidade. Agora, podemos pensar no tamanho da dor, e no valor que tem a vida sobre a doença. (Aluna B).

Senti muita satisfação, alegria em poder ajudar a paciente a esquecer um pouco a sua doença. Observar o entusiasmo daquela senhora criando uma obra artística encheu minha alma de alegria. Com certeza, não [foi] só a paciente [que] se sentiu melhor, eu também. Foi uma terapia recíproca. (Aluna C).

Essa experiência foi gratificante. Além de ajudar a paciente a passar o tempo, fez com que ela se sentisse produtiva, afastando-a mentalmente do ambiente hospitalar. Senti-me muito bem. (Aluna D).

Eu me senti muito bem. Levantou meu astral, por ver que pude ajudar a dar, de alguma forma, alegria à paciente. Eu me senti útil e agradável. (Aluna E).

Ótima experiência, pois permitiu ao paciente desenvolver seu lado comunicativo e interagir com 0 próximo apesar de estar retraído. (Aluna F).

Fiquei encantada com o processo. Aprendique poderei, com criatividade ampliar o leque de técnicas para cuidar melhor do paciente, desde que ele, ... se sinta melhor. (Aluna G).

Pela posição expressada pelas estudantes que participaram da experiência pode-se destacar que elas descobriram que a assistência de enfermagem em oncologia pode ser realizada de uma maneira diferente das abordagens técnicas habituais em tal cenário hospitalar. Elas revelaram seu encanto e sua surpresa com a riqueza encontrada em uma estratégia aparentemente simples adotada para direcionar o ócio dos pacientes, que estão passando por um período delicado em seu processo saúde-doença.

Mais do que isto, a experiência mostrou para as estudantes, um novo ângulo dos pacientes, que apresentaram uma riqueza de expressões, sentimentos e emoções tanto relativos a situação que experimentavam, como em relação à sua vida e às suas

\section{Referências}

1.Paim RCN. Problemas de enfermagem eaterapia centrada nas necessidades do paciente. Rio de Janeiro (R): União dos Cursos Cariocas; 1978.

2. Dahlke R. A doença como linguagem da alma: os sintomas como oportunidade de desenvolvimento.Tradução de Dante Pignatari.São Paulo (SP):Cultrix;2002.

3. Pinkus L. Psicologia do doente. Tradução de João Aníbal G. S. Ferreira. São Paulo (SP): Paulinas; 1998.

4. Pain S, Jarreau G. Teoria e técnica da arteterapia: a compreensão do sujeito. SãoPaulo (SP): Artes; 1982.

5.DeMasiD, RusselB, LafargueP.AEconomia do ócio. 2ed. Tradução: Carlos lineu W. Costa, Pedro Jorgensen Júnior, Lea Manzi. Rio de Janeiro (R): Sextante; 2001.

6. Hagedorn R. Fundamentos da prática da terapia ocupacional Tradução de José Batista São Paulo (SP): Dynamis I; 1999.

7. Oliveira J, GarcezL. Explicando a arte: uma iniciação para entender e apreciar as artes visuais. Rio de Janeiro (RJ): Ediouro;2001.

8. Haack AW,coordenador. Oteste das cores de Lüscher: o extraordinário teste que revela a personalidade através da cor. Rio de Janeiro (R)): RENES; 1969. lembranças. Este novo ângulo revela a arteterapia, como uma estratégia artística, que pode atender à suas necessidades emocionais e afetivas dos pacientes, como uma técnica que se afasta de intervenções de enfermagem rotineiramente empregadas.

\section{CONSIDERAÇÕES FINAIS}

0 ser humano é o único ser capaz de interagir consigo e com os outros seres, afetando o mundo e sendo afetado por ele; tendo anseios profundos de ser amado e de ser importante - importante para alguém. Existe uma relação dinâmica entre o mundo real e o sujeito observado; o sujeito observador faz parte do processo de conhecimento e interpreta os fenômenos de acordo com seus valores e crenças, dando-lhes um significado.

Assim, confirmaram-se as aproximações à suposição da existência de uma ligação, no ser humano, entre pensamentos, comportamentos e sentimentos ${ }^{8}$. Em conseqüência desta suposição do (QRA) da Arteterapia, os pacientes, enquanto indivíduos disfuncionais, puderam ser ajudados a se tornarem mais funcionais por meio da análise de seus processos cognitivos, pela melhora das estratégias do conhecimento e da aprendizagem e, pelo ensino de estratégias cognitivas eficazes, que substituíram as estratégias mal adaptadas, negativas ou ineficazes. A outra suposição implicitamente adotada na experiência, diz respeito às alunas participantes. Elas declararam que se sentiram estimuladas e gratificadas com a experiência.

0 Teste de Lüscher é realmente uma técnica que possibilitou reflexões sobre a personalidade dos pacientes através das cores, e que enriqueceu esta experiência. E finalmente, só uma terapia centrada no paciente, como a arteterapia, pode levar à compreensão dos problemas e das emoções dele, resultando num processo assistencial humano e na conseqüente realização profissional de quem o realiza / executa.

\section{Sobre as Autoras}

\section{Izabel Cristina Falcão Juvenal Barbosa}

Terapeuta Ocupacional pela Universidade de Fortaleza. Mestre em Enfermagem pela Universidade Federal do Ceará.

\section{Míria Conceição Lavínas Santos}

Enfermeira do INCA. Doutoranda em Enfermagem pela Universidade Federal do Ceará.

\section{Glória da Conceição Mesquita Leitão}

Enfermeira. Doutora em Saúde Pública. Professora Adjunta da Universidade Federal do Ceará. 